\title{
The Evaluation of Learning Assessment in Higher Education: from the perception of students to the ideal evaluation
}

\author{
Carlos Arriaga Costa \\ University of Minho, \\ School of Economics and Management, Portugal \\ Orlando Petiz Pereira \\ University of Minho, \\ School of Economics and Management, Portugal
}

\begin{abstract}
Pedagogical practices in higher education have been experiencing important changes, most of which are in line with the principles of the Bologna Reform. The new learning methodologies seem to have prompted different procedures in the evaluation process. The programs were redesigned to respond to an environment, which is ever more competitive. As a result, the ideas of excellence and efficiency embody the objectives of teaching and the result of evaluation of students came to be regarded as a fundamental tool in the selection process and visibility. This study aims at analyzing in-depth the experiences of evaluation of undergraduate students (1st cycle) and graduate students (2nd cycle) in two different periods: the first covering for the years of 2008 and 2009 and the second for 2016 and 2017 . These periods are two important milestones in the implementation of the Bologna Declaration because they mirror the beginning and the progress of the Bologna Reform. This study does also seek to identify the reasons, which enshrine the perceptions of evaluation experiences and the meaning of the ideal model of evaluation. Although the sensitivity/uneasiness does persist in the evaluation perception, this study's results seem to be rather relevant.
\end{abstract}

Key words: Evaluation in the University; Learning Assessment; Teaching and Learning according to Bologna.

\section{INTRODUCTION AND OBJECTIVES}

Education is a treasure which must be cherished by citizens. Hence, universities, such as the education and training institutions, should shape the student's thinking as well all agents involved in the teaching-learning process in order to relocate them in society and make them committed beings, responsible and happy, and who might be able to live as social beings and understand the world around them (Martínez, 2010). In this sense, Universities should motivate and encourage the development of academia, through the adoption of dynamic, constructive, inclusive, integrative and interactive models of education. In this process, evaluation is a strategic instrument for all elements within the educational community and other stakeholders. In fact, evaluation, in its various forms, would motivate students, both at the cognitive and creative activity levels throughout the educational process.

Therefore, Chen and Hushower (2003) underline the need for various pedagogical methods of teaching that can be applied differently in each course or discipline. On the other hand, the accommodation process of the pedagogical model to the curricular context is slow and it should be phased out (Arriaga, 2009). In another aspect, Struyven, Dochy and Janssens (2005) state that students perceive their learning environment in such a way that it determines the degree and how they learn and involve themselves in the process. In this light, learning would 
relate itself to educational practices. In this line of thought, the authors state that the student reacts differently to an evaluation based on memorisation and the undergoing of mere routines, thereby accepting it (the evaluation process) as an imposition. Along these lines, the student would perceive this type of evaluation as "arbitrary" and "irrelevant". The authors refer to the importance of discussing at length about the mismatch between what the teacher plans and his learning objectives with what is perceived by the students about the very same plan.

Given the importance of evaluation in the process of learning and teaching in the student's personal and social development, this study aims at shedding light upon the experiences and perceptions about the evaluation and which students retain. They spring from experiences, either as students who attended, in the recent past, secondary school, or students who already have some university experience. It is intended also to emphasise that experiences in different education models can translate different perceptions of the university students on the evaluation process.

Having in mind the aforementioned objectives, we have conducted an enquiry regarding the university students' perception of evaluation. The enquiry was realised in two different moments along the implementation of the Bologna Declaration. The first was undergone a few years after the implementation of the Bologna process and the second one was held at a later stage, whilst relying upon the maturity of the process itself. This second phase also coincides with a critical juncture, where we undertake and incisive discussion about the development of the teaching-learning process. The data from the first phase relates to the years of 2008 and 2009, whereas the second timeline refers to the year 2016 and 2017.

The questionnaire focused on convenience samples of Bachelor and Master students pursuing programmes as offered by the School of Economics and Management and the School of Law, University of Minho, headquartered in the North of Portugal. The design of the questionnaire was an integrating part of the Centre of the Research in Education (CIED) project at the University of Minho "TPU - Transformar a Pedagogia na Universidade" (TPU-transforming Pedagogy at the University) started in 2006. Now, in this latest phase, we intend to identify the reasons for the different evaluation perceptions over time, that is, upon the students' admission to the University, and at the moment of completion of their degree, for the two moments of inquiry. Similarly, we also intend to compare and collate the results of students ' perceptions, for the two cycles of University studies (1st cycle 2 nd cycle). With regard to the second cycle, this study does only include respondents from the second timeline.

Our investigation resorts to the literature review to contextualising and structuring the subject. It then presents the methodology, the population and the size of the sample, before analysing the results. Subsequently, we finalise with the discussion and conclusion, followed by the bibliographic references.

\section{CONTEXTUALISATION AND REFERENCES}

Overall, the Bologna Declaration has been implemented in almost all European universities for more than fifteen years. Its implementation has led to structural curriculum adjustments in order to facilitate and nurture convergence of the courses to a greater academic and professional acceptance (Pereira and Costa, 2017a). As a result, higher education has undergone important metamorphoses, either in terms of the curriculum of the courses, of the academic curricula and in terms of various cross-training related aspects, particularly evaluation methodologies. (Pereira and Costa, 2017b). In light of this, we believe that the strategy for universities for teaching, should include (1) a redefinition of the educational offer 
(be more competitive), (2) a new design of each programme curriculum (including more efficient courses), (3) collaboration between universities and other institutions (establishment of cooperation and agreements), (4) a more open, transparent and accountable academic system to facilitate the comparison among the courses, according to common criteria. Nonetheless, Vieira et al. (2004), suggest that changes stimulate the adoption of resisting attitudes to change, not just because these changes are associated with problems of independence of teachers, which are seen not only as processes of providing explanations about their work but also with the lack of conditions and resources.

Tavares et al. (2004) acknowledge the existence of discontinuities in the transition between the various teaching and learning contexts. The transition and their differences combine aspects of psychosocial development with the autonomy of students in learning processes and transmit a variety of relationships between the various psychological, personal and contextual variables. According to these authors, universities have a diversity of students with multiple backgrounds, different conditions and with various causes of school abandonment and academic insuccess. Therefore, we should rethink the learning mission of the student because it goes far beyond the acquisition of knowledge and scientific and technical skills (Correia and Pereira, 2009; Pereira and Coutinho, 2009).

Having in mind the aforementioned context of change, there arises the need for calibration and adjustment of higher education to the real societal needs, which was already underlined by Lyotard (1979). He defends that university education is characterised by uncertainty and ambiguity. Hence, new academic practices materialise in a more competitive environment that goes beyond the social domain and require profound changes in the relationship between the University, knowledge and society (Light and Cox, 2001). In this manner, the ideas of "excellence" and "efficiency" became more significant because they are important signs to be observed in order to improve progress and development. As the education's mission envisions to train people and render them able to exercise, responsibly, their rights and duties as citizens, it seems urgent to look at the educational process as one and not as the sum of independent parts. Therefore, the issues of sustainability, which are on the citizens' agenda, must be integrated thematically in courses (Dmochowski et al. 2016), for developing students holistically because humans are co-creators of the economic and social systems (Chen et al. 2017; Pereira and Costa, 2017b).

Evaluation is an important step in the learning process. From the teachers perspective, it is the time to clarify the results of teaching and, for students, it is the time to appraise the results of their own academic performance, either within and outside the classroom. The evaluation is intended to clarify the success of the educational process. However, the characteristics of the academic environment affect, similarly, the learning outcomes, both at the overall level of the institution and the individual level (Lizzio, Wilson and Simons, 2002).

According to Nygaarda and Belvigib (2011), the teaching-learning model can be seen through the lenses of the perspective of context or from the perspective of the decontextualization. The latter one associates learning to the acquired knowledge. Therefore, knowledge is associated with what is reprinted in textbooks. In this decontextualised concept of the teaching-learning process, teaching is standardised and it is applied in the same manner anywhere, whilst complying with a standardisation form of the teaching-learning process. On the contrary, in a contextualised design of learning, the process involves a knowledge construction that is not limited nor aimed at a simple acquisition of knowledge. It is a constructivist line of thought where knowledge is constructed on a permanent and dynamic interaction of previous knowledge production and social activity. This posture is nurtured by advocates of learning 
based on service-learning approaches, whose results are not limited only to the person who is involved. Their positive effects range from personal development to social, community, cognitive, relational and economic development. There are other approaches besides the service-learning such as problem-based learning, reflective learning and case based learning that can be built in a constructive line, envolving not only knowledge but atitudes and procedures as recommended by the Bologna Declaration.

Yet, students have had perceptions of evaluation which oscilate between the positive and negative perceptions. For them, moments of evaluation, especially those relying on partial and/or final examinations, are sources of stress. Many students make a negative evaluation of these moments and they believe that tests fail to give the opportunity to demonstrate their efforts to academically perform. Therefore, they defend that the process should give emphasis to the number of hours of work and also to the correspondence between what is required and what is learned during working hours. According to Chen and Hushower (2003), the introduction of a teaching-learning model based on "competence" involves a scoring and ranking system. This procedure would make it possible to improve the quality of monitoring of each discipline of the programme and would promote a more methodological and more autonomous scientific research. In this process, the teacher would be responsible for the management of learning which involves the student's motivation in his/her learning process. The teacher would be the student's coordinator and consultant. But the role of the teacher can change over time. In addition, and according to Chen and Hushower (2003), the tests would be just a way of controlling knowledge, along with other evaluation tools.

\section{Methodology, sample and procedures}

\section{INVESTIGATION RESULTS}

The main objective of our study is to determine the different perceptions of University students on the evaluation process, in two periods of inquiry: the first in the years 2008 and 2009 and the second in 2016 and 2017. The second period of inquiry relates to a time of discussion and questioning of the results of some aspects of the changes in the curricula of courses, with the implementation of the Bologna process. We also intend to verify the effective experience of evaluation of students corresponding to their ideal perceptions of evaluation, and also if these perceptions have modified and evolved during these periods.

We applied the questionnaire referred to in the introduction and entitled "A Avaliação - 0 que pensam os Alunos?" (The Evaluation - What do students think?). This questionnaire was previously validated in classroom by several departments of the University of Minho.

The target population were first cycle students pursuing the Bachelors in Public Administration (PA), Accounting (CONT), (D) and Economy (ECON), and second cycle students pursuing the Masters in Monetary, Banking and Financial Economics (MEMBF) and Social Economics (MES) of the School of Economics and Management, University of Minho. The empirical research seeks to answer the following questions:

(1) Are there statistically significant differences in the perception of first-year students as compared to other school years of the first cycle, in what concerns what they think about the evaluation process?

(2) Are there statistically significant differences in the perception of the first cycle students in relation to the 2 nd cycle students about what they think about the evaluation process? The first question stems from the fact that the first-year students have an evaluation experience which results from their recent experience in secondary education, while the remaining students have already consolidated their evaluation experience in line with higher education models. The second question arises from the 
fact that the learning model presents differences between the first cycle and second cycle programmes, particularly with regard to the best interests of application of knowledge by students attending 2nd cycle programmes.

(3) Has the implementation of the Bologna Declaration geared changes in the perception of evaluation in both periods?

The first group of questions of the questionnaire seeks to understand the students' perception about evaluation, considering their experiences of evaluation, whether cognitive or emotional in both enquiry moments. To this end, we have included the following 11 perception items, levelled from 1 to 5 , where the value one corresponds to the feeling of negative evaluation, whereas five corresponds to a more positive perception. The items used were: (i) injusticeJustice; (ii) Insecurity-Self-confidence; (iii) Nervousness-Calmness; (iv) Luck-Competence; (v) Obstacle-Challenge; (vi) Imposition-Choice; (vii) Conformity-Critical Thinking; (viii) Competition-Cooperation; (ix) Memorisation-Reflection; (x) Non-Motivation-Motivation; (xi) Ranking-Progression.

The second group of questions aims at analysing the perception of what is ideal for students. In addition, the aim is to determine if, through the two moments of inquiry, there are differences in the two generations of students. Under these circumstances, students, hierarchically, chose the four items of evaluation perception which correspond to the four ideas that, for them, best reflect the ideal image/perception. However, students still had the freedom to add a fifth item. We have looked at the third question, this time openly, about what is perceived by the students about the evaluation process, from a sentence of Hadji (1994) that compares the evaluation to a game. This question, aims to deepen the analysis of the emotional and cognitive features of evaluation, and what represents the evaluation in the academic path of the student.

As already, mentioned different students implemented the questionnaire in two moments. In the first period, 324 bachelor students replied to the questionnaire, of which $47 \%$ of the respondents pursue the Bachelor Degree in Economics and 53\% pursue the Bachelor Degree in Law. If one considers the Bachelor's year of study, 54\% are first-year students and $46 \%$ attend other years. According to the gender of students, $61 \%$ are female and $39 \%$ are male. 74 students did not indicate their gender, which accounts for the discrepancies between the total number of students and the gender totals in the calculation of percentages.

In the second period, we collected 216 questionnaires, where $63.9 \%$ of the respondents were 1 st cycle students and $36.9 \%$ were 2 nd cycle students. Of the respondents, $32.3 \%$ are male and $65.4 \%$ female and $2.3 \%$ have failed to indicate their gender. In addition, 35\% attended the first year of the undergraduate degree, $12 \%$ attended the 2 nd year, $15.7 \%$ attended the third year. $36.9 \%$ were graduate students attending the 1 st year of the masters' programmes.

To begin with, we realised an analysis of the distribution of the two samples to control for the assumptions of normality. To this end, we used the Kolmogorov-Smirnov statistics that showed that verified/ensured the normality of distribution.

Apparently, there seem to be some discrepancies in the structure of the two samples, which made it necessary to run various statistical tests in order to determine if these differences were statistically significant or not. Thus, we have run T-tests based on averages and F-tests based on frequencies in order to determine the existence of significant differences or not. Evidence underpinned only statistically significant differences between the two samples for the following variables: Question A number (iii): Nervousness-Calmness ( $p$ value $=0.037$ when one admits a 5\% error); Question B reference (viii of question A) Ideal Perception of 
Competence Evaluation ( $\mathrm{p}$ value $=0.013$ when one admits a $5 \%$ error $5 \%$ ). Considering that the existing significant differences are only two, we were confident in resorting to a joint analysis of the two subsamples.

\section{Analysis of Results \\ Ideas associated with the evaluation as perceived by students and in line with their experience}

Overall, the relative frequency of responses to the perception of students on the evaluation unveils that students have a reasonably positive perception of evaluation. They tend to associate it with the development of competence critical values, progression, of reflection, motivation and justice other than conformity, luck, ranking, memorisation, discouragement or injustice. However, justice in the evaluation process is an item that worries students and it induces stress.

Table 1: Frequency of responses in each item of perception of evaluation by moments of inquiry

\begin{tabular}{|c|c|c|c|c|c|c|}
\hline \multirow{2}{*}{ Itens of perception } & \multicolumn{6}{|c|}{ Relative frequency } \\
\hline & 1 & 2 & 3 & 4 & 5 & Omisso \\
\hline 1st Period $2008 \& 2009$ & & & & & & \\
\hline Injustice-Justice & $3.4 \%$ & $10.3 \%$ & $34.2 \%$ & $43.1 \%$ & $8 \%$ & $0.9 \%$ \\
\hline $\begin{array}{l}\text { Lack of Confidence-Self } \\
\text { confidence }\end{array}$ & $1.7 \%$ & $10.6 \%$ & $46 \%$ & $34.5 \%$ & $6 \%$ & $0.0 \%$ \\
\hline Nervousness-Calmness & $6.6 \%$ & $20.4 \%$ & $38.2 \%$ & $25.3 \%$ & $9 \%$ & $0.0 \%$ \\
\hline Luck-Competence & $2.9 \%$ & $9.5 \%$ & $33 \%$ & $33.4 \%$ & $36.6 \%$ & $1.1 \%$ \\
\hline Obstacle-Challenge & $2.6 \%$ & $7.5 \%$ & $35.3 \%$ & $41.4 \%$ & $11.5 \%$ & $1.7 \%$ \\
\hline Imposition-Choice & $3.7 \%$ & $12.9 \%$ & $36.5 \%$ & $33.6 \%$ & $10.6 \%$ & $0.3 \%$ \\
\hline Conformism-Critical Thinking & $1.1 \%$ & $8 \%$ & $35.1 \%$ & $40.8 \%$ & $13.2 \%$ & $1.7 \%$ \\
\hline Competition-Cooperation & $7.2 \%$ & $10.1 \%$ & $27.3 \%$ & $34.2 \%$ & $20.4 \%$ & $0.0 \%$ \\
\hline Memorisation-Reflection (1) & & & & & & $100 \%$ \\
\hline Desmotivation- Motivation (1) & & & & & & $100 \%$ \\
\hline Ranking-Progression (1) & & & & & & $100 \%$ \\
\hline 2nd Period 2016 and 2017 & & & & & & \\
\hline Injustice-Justice & $0.9 \%$ & $6.5 \%$ & $27.2 \%$ & $54.8 \%$ & $9.7 \%$ & $0.9 \%$ \\
\hline $\begin{array}{l}\text { Lack of Confidence-Self } \\
\text { confidence }\end{array}$ & $0.0 \%$ & $14.3 \%$ & $37.8 \%$ & $44.7 \%$ & $2.3 \%$ & $0.9 \%$ \\
\hline Nervousness-Calmness & $12 \%$ & $27.6 \%$ & $40.1 \%$ & $16.6 \%$ & $3.2 \%$ & $0.5 \%$ \\
\hline Luck-Competence & $1.8 \%$ & $7.4 \%$ & $26.7 \%$ & $46.5 \%$ & $16.6 \%$ & $0.9 \%$ \\
\hline Obstacle-Challenge & $1.4 \%$ & $5.1 \%$ & $29.5 \%$ & $48.4 \%$ & $15.2 \%$ & $0.5 \%$ \\
\hline Imposition-Choice & $8.3 \%$ & $13.4 \%$ & $33.2 \%$ & $31.8 \%$ & $12.4 \%$ & $0.9 \%$ \\
\hline Conformism-Critical Thinking & $1.8 \%$ & $7.8 \%$ & $35.9 \%$ & $41.9 \%$ & $12 \%$ & $0.5 \%$ \\
\hline Competition-Cooperation & $3.7 \%$ & $10.1 \%$ & $27.2 \%$ & $43.8 \%$ & $14.3 \%$ & $0.9 \%$ \\
\hline Memorisation-Reflection (1) & $2.8 \%$ & $13.8 \%$ & $33.2 \%$ & $37.3 \%$ & $12.4 \%$ & $0.5 \%$ \\
\hline Desmotivation- Motivation (1) & $0.5 \%$ & $7.8 \%$ & $27.6 \%$ & $46.1 \%$ & $17.5 \%$ & $0.5 \%$ \\
\hline Ranking-Progression (1) & $0,5 \%$ & $5.5 \%$ & $23.5 \%$ & $54.8 \%$ & $13.8 \%$ & $1.8 \%$ \\
\hline
\end{tabular}

Source: Coauthors estimations

(1)_Perception variables introduced only the second evaluation moment

Evidence of the students' perceptions in both evaluation moments does not seem to underpin diferences statistically significant for all observed itens. Would such a result mean that the perception of evaluation has no changes over this period, notwithstanding the introduction of the teaching-learning models?

In the second period of inquiry were introduced three new variables of perception: Memorisation-Reflection, Demotivation-Motivation and Raking-Progression. These have outshined regarding the positive perception students in the 2 nd moment of evaluation. 
However, it continues to reveal greater positive perception in both moments: cooperation and justice in the evaluation process. In the first period of inquiry, it first registers critical thinking and competence (see table 2).

Table 2: Five variables were perceived with greater appreciation by students, by moments of

\begin{tabular}{lcc}
\multicolumn{1}{c}{ inquiry } & & \\
\hline Item of Perception of evaluation & Mean & $\begin{array}{c}\text { Standard } \\
\text { Deviation }\end{array}$ \\
\hline 1st Period 2008 \& 2009 & & \\
1. Conformism-Critical Thinking & 3.58 & 0.87 \\
2. Luck-Competence & 3.56 & 0.98 \\
3. Obstacle-Challenge & 3.53 & 0.89 \\
4. Competition-Cooperation & 3.51 & 1.14 \\
5. Injustice-Justice & 3.42 & 0.91 \\
& & \\
2nd Period 2016 and 2017 & & \\
1. Conformism-Critical Thinking & 3.77 & 0.78 \\
2. Luck-Competence & 3.73 & 0.86 \\
3. Obstacle-Challenge & 3.71 & 0.84 \\
4. Competition-Cooperation & 3.69 & 0.90 \\
5. Injustice-Justice & 3.67 & 0.78 \\
\hline
\end{tabular}

Source: Coauthors estimations

However, there were statistically significant differences in negative items pertaining to Injustice and Nervousness, whilst allowing to observe in the item Injustice-Justice some heterogeneity of variance, whereas one can observe homogeneity of variance in what regards the Nervousness-Calmness item:

$>$ Injustice-Justice:

$\mathrm{F}(526)=6.89, \mathrm{p}=0.01, \mathrm{t}(418.2)=-2.98, \mathrm{p}=0.003$, Mean (1st moment) $=3.42, \mathrm{dp}=0.91$ $<$ Mean (2nd moment $)=3.65, \mathrm{dp}=0.79$.

$>$ Nervousness-Calmness

$\mathrm{F}(528)=0.33, \mathrm{p}=0.57, \mathrm{t}(528)=3.63, \mathrm{p}<0.001$, Mean (1st moment) $=3.1, \mathrm{dp}=1.04>$ Mean (2nd moment) $=2.76, \mathrm{dp}=0.96$.

Thus, the perception of injustice concerning the evaluation is relatively more present in the first moment of inquiry, but the perception of nervousness is more present in the second one, which represents an average value below 3 .

We have looked at statistically significant differences per programmes, gender and years of study in the two moments of inquiry and found differences in the following variables:

Differences per programme:

(1) of injustice-justice ( $\mathrm{p}$ value $=0.005$ whenever one admits an error of $5 \%$ );

(2) of luck or bad luck-competence ( $\mathrm{p}$ value= 0.04 whenever one admits an error of $5 \%$ );

(3) of imposition-choice ( $\mathrm{p}$ value $=0.003$ whenever one admits an error of $5 \%$

(4): of conformism-critical thinking (and with some significance, $\mathrm{p}$ value $=0.086$ whenever one admits an error of $5 \%$ ).

\section{Differences per gender:}

(1) of insecurity-self-confidence ( $\mathrm{p}$ value $=0.006$ whenever one admits an error of $5 \%$ );

(2) of nervousness-calmness ( $\mathrm{p}$ value $=0.009$ whenever one admits an error of $5 \%$ ).

\section{$>$ Differences per year of studies:}

(1) of injustice-justice ( $\mathrm{p}$ value $=0.032$ whenever one admits an error of $5 \%$ );

(2) of obstacle-challenge ( $\mathrm{p}$ value $=0.05$ whenever one admits an error of $5 \%$ ). 
With regard to the courses of the students surveyed, they were divided into bachelor degree courses (1st cycle) and the master degree courses (2nd cycle courses). As regards the students' perception about the evaluation according to their experience, all items obtained an average between 3 and 4, both bachelor and master degree courses. Regardless of the moments of inquiry, only statistically significant differences were observed between the responses of the bachelor students and masters students in the insecurity-self-confidence and memorisationreflection items, in which students of the bachelor degree seem to perceive less self-confidence and, interestingly, the masters' students perceive less thinking on evaluation:

$\checkmark$ insecurity-self-confidence: $\mathrm{F}(181)=0.72, \mathrm{p}=0.4, \mathrm{t}(181)=-2.28, \mathrm{p}=0.02$, Mean (Bachelor Degrees $)=3.31, \mathrm{dp}=0.76$ $<$ Mean (Master Degrees) $=3.6, \mathrm{dp}=0.71$

$\checkmark$ memorisation-thinking: $\mathrm{F}(182)=2.31, \mathrm{p}=0.13, \mathrm{t}(182)=2.22, \mathrm{p}=0.03$, Mean (Bachelor Degrees) $=3.53, \mathrm{dp}=$ $0.99>$ Mean (Master Degrees) $=3.17, \mathrm{dp}=0.89$

Combining the variable gender and courses, we only found statistically significant differences in the answers given by the female students in the insecurity-self-confidence and impositionchoice variables, where the undergraduate female students registered less self-confidence and the graduate female students perceive evaluation as something imposed rather than a choice:

$\checkmark$ insecurity-self-confidence (female):

$\mathrm{F}(121)=0.006, \mathrm{p}=0.94, \mathrm{t}(121)=-2.63, \mathrm{p}=0.01$, Mean (Bachelor Degrees) $=3.19 \mathrm{dp}=$ $0.75<$ Mean (Master Degrees) $=3.59, \mathrm{dp}=0.74$

$\checkmark$ imposition-choice (female):

$\mathrm{F}(121)=0.21, \mathrm{p}=0.65, \mathrm{t}(121)=2.29, \mathrm{p}=0.02$, Mean (Bachelor Degrees) $=3.46, \mathrm{dp}=$ $0.99>$ Mean (Master Degrees) $=2.97, \mathrm{dp}=1.16$

Only bachelor courses were the object of comparison between the two periods. Evidence underpins that while the first period justice variable seems to have weighed more on the perception of undergraduate students, the second one seems to have been the nervousness variable caused by the evaluation:

$\checkmark$ injustice-justice:

$\mathrm{F}(455)=2.96, \mathrm{p}=0.09, \mathrm{t}(455)=-2.86, \mathrm{p}=0.004$, Mean (1st period) $=3.37, \mathrm{dp}=0.89<$ Mean (2nd period) $=3.63, \mathrm{dp}=0.81$

In general terms and with respect only to the first period of inquiry, we have seen that the students pursuing the course of law noted more negative perceptions regarding the injustice of the assessment as compared to the students pursuing the course of Economics.

$\checkmark$ nervousness-calmness

$\mathrm{F}(457)=0.37, \mathrm{p}=0.55, \mathrm{t}(457)=2.5, \mathrm{p}=0.01$, Mean (1st period $)=3.02, \mathrm{dp}=1.02>$ Mean $(2 \mathrm{nd}$ moment $)=2.76, \mathrm{dp}=0.97$.

With regard to responses by gender in the two moments of inquiry, male students gave statistically significant different responses in the items justice-injustice; nervousness-calmness and obstacle-challenge, as summarised below:

$\checkmark$ justice-injustice (male): $\mathrm{F}(162)=1.63, \mathrm{p}=0.2, \mathrm{t}(162)=-2.18, \mathrm{p}=0.03$, Mean (1st period) $=3.27, \mathrm{dp}=0.97<$ Mean (2nd period) $=3.60, \mathrm{dp}=0.84$

$\checkmark$ nervousness-calmness (male) $\mathrm{F}(162)=3.45, \mathrm{p}=0.07, \mathrm{t}(162)=2.2, \mathrm{p}=0.03$, Mean $(1$ st period $)=3.28, \mathrm{dp}=0.96>$ Mean $(2 \mathrm{nd}$ period $)=2.95, \mathrm{dp}=0.87$. 
$\checkmark$ obstacle-challenge (male)

$\mathrm{F}(161)=2.77, \mathrm{p}=0.1, \mathrm{t}(161)=-1.62, \mathrm{p}=0.1$, Mean $(1 \mathrm{st}$ period $)=3.54, \mathrm{dp}=0.84<$ Mean $(2 \mathrm{nd}$ period $)=3.76 \mathrm{dp}=0.76$.

Although we estimate a probability error of $10 \%$, it seems that the male students in the first period perceive the evaluation to a lesser extent as a challenge than students in the second period. With regard to female students, we only observed significant differences in the justiceinjustice variable, in which the students perceived this variable less positively in the first period of inquiry than in 2nd one:

$\checkmark$ justice-injustice (female):

$\mathrm{F}(286)=0.82, \mathrm{p}=0.37 \mathrm{t}(286)=-2.5, \mathrm{p}=0.01$, Mean $(1$ st period $)=3.44, \mathrm{dp}=0.78<$ Mean $(2 \mathrm{nd}$ period $)=3.67 \mathrm{dp}=0.77$

Moreover, and still considering the perception of evaluation items by students, we have controlled for the consistency of responses, respectively in the degree of perception of the items associated with emotional perceptions or other more associated with rational perceptions. To this end, we resorted to the use of the average/mean pairwise comparison process, considering the two periods of inquiry, gender and years of attendance of courses.

Overall, we pinpointed different response patterns in about half of the items considered. The male students do not seem to account for significantly different response patterns in the following pairs of perception of evaluation: injustice-justice and insecurity-self-confidence; competition-cooperation and luck-competence; luck-competence and motivationdemotivation; obstacle-challenge and motivation-demotivation; obstacle-challenge and conformity-critical thinking (see table 3).

Insofar the female students are concerned, we did not observe significantly different response patterns in the following pairs of items: injustice-and-justice mission; competition-cooperation and luck-competence; luck-competence and motivation-demotivation; obstacle-challenge and motivation-demotivation; obstacle-challenge and conformity-critical thinking (see table 3).

Table 3: A paired sample of the evaluation perception items by gender

\begin{tabular}{lccclccc}
\hline Paired items & $\begin{array}{c}\text { Difference } \\
\text { statistics } \\
\text { (Mean) }\end{array}$ & DP & $\begin{array}{c}\text { P } \\
\text { values }\end{array}$ & Paired items & $\begin{array}{c}\text { Difference } \\
\text { statistics } \\
\text { (Mean) }\end{array}$ & DP & $\begin{array}{c}\text { P } \\
\text { values }\end{array}$ \\
\hline $\begin{array}{l}\text { Male Students } \\
\text { injustice-insecurity }\end{array}$ & - & 1.01 & 0.65 & $\begin{array}{l}\text { Female Students } \\
\text { injustice-insecurity }\end{array}$ & 0.29 & 0.840 & 0.00 \\
insecurity-nervousness & 0.034 & & & & & & \\
injustice-nervousness & 0.324 & 0.96 & 0.00 & insecurity-nervousness & 0.52 & 0.95 & 0.00 \\
injustice-luck & -0.26 & 1.13 & 0.00 & injustice-nervousness & 0.81 & 1.17 & 0.00 \\
competition-luck & -0.16 & 1.16 & 0.00 & injustice-luck & -0.02 & 0.95 & 0.67 \\
luck-demotivation & 0.19 & 1.12 & 0.17 & competition-luck & 0.016 & 1.01 & 0.78 \\
obstacle-demotivation & 0.11 & 1.12 & 0.42 & obstacle-demotivation & -0.14 & 1.1 & 0.15 \\
obstacle-conformity & 0.12 & 1.08 & 0.12 & obstacle-conformity & -0.03 & 1.09 & 0.36 \\
imposition-competition & -0.27 & 1.22 & 0.00 & imposition-competition & -0.23 & 1.27 & 0.61 \\
& & & & & & 0.00 \\
\hline
\end{tabular}

\section{Source: coauthors' calculations}

With regard to the duration of the programmes (number of years students attend courses till completion of degree), the students attending the first year of their bachelor degree have shown statistically significant differences in the following pairs of items: injustice-justice and insecurity-self-confidence; insecurity-self-confidence and nervousness-calmness; injusticejustice and nervousness-calmness; injustice-justice and luck-competence; obstacle-challenge and demotivation-motivation (see table 4). 
Concerning the year students attend, those attending the 2nd year of the bachelor degrees, they unveil statistically significant differences in the following pairs of items insecurity-selfconfidence and nervousness-calmness; injustice-justice and nervousness-calmness (see table 4).

Insofar the bachelors' duration is regarded, students attending the third year of their course, we found statistically significant differences in the following pairs of items: insecurity-selfconfidence and nervousness-calmness; injustice-justice and nervousness-calmness; obstaclechallenge and motivation-demotivation; imposition-choice and competition-cooperation (see table 4).

Regarding the duration of the master programmes, students pursuing the first year depict statistically significant differences in the following pairs of items: injustice-justice and insecurity-self-confidence; insecurity-self-confidence and nervousness-calmness; injusticejustice and nervousness-calmness; competition-cooperation and luck-competence; obstaclechallenge and conformism-critical; imposition-choice and competition-cooperation (see table 4).

Table 4: A paired sample of perception of evaluation by academic years

\begin{tabular}{|c|c|c|c|c|c|c|c|}
\hline Paired items & $\begin{array}{l}\text { Difference } \\
\text { statistics } \\
\text { (Mean) }\end{array}$ & DP & $\begin{array}{c}\mathrm{P} \\
\text { value }\end{array}$ & Paired items & $\begin{array}{l}\text { Difference } \\
\text { statistics } \\
\text { (Mean) }\end{array}$ & DP & $\begin{array}{c}\mathrm{P} \\
\text { values }\end{array}$ \\
\hline Bachelor Year 1 & & & & Master Year 1 & & & \\
\hline injustice-insecurity & 0.13 & 1.02 & 0.04 & injustice-insecurity & 0.30 & 0.88 & 0.00 \\
\hline insecurity-nervousness & 0.38 & 0.99 & 0.00 & insecurity-nervousness & 0.79 & 0.99 & 0.00 \\
\hline injustice-nervousness & 0.51 & 1.37 & 0.00 & injustice-nervousness & 1.1 & 1.12 & 0.00 \\
\hline injustice-luck & -0.17 & 1.05 & 0.01 & injustice-luck & -0.05 & 1.01 & 0.69 \\
\hline competition-luck & -0.07 & 1.06 & 0.28 & competition-luck & -0.28 & 1.10 & 0.02 \\
\hline luck-demotivation & -0.20 & 1.14 & 0.14 & luck-demotivation & 0.06 & 1.09 & 0.61 \\
\hline obstacle-demotivation & -0.33 & 1.16 & 0.02 & obstacle-demotivation & 0.06 & 1.09 & 0.61 \\
\hline obstacle-conformity & -0.03 & 1.06 & 0.67 & obstacle-conformity & 0.28 & 1.09 & 0.03 \\
\hline imposition-competition & -0.13 & 0.78 & 0.09 & imposition-competition & -0.33 & 1.37 & 0.04 \\
\hline $\begin{array}{l}\text { Bachelor Year } 2 \\
\text { iniustice-insecurit }\end{array}$ & & & & Bachelor Year 3 & & & \\
\hline $\begin{array}{l}\text { injustice-insecurity } \\
\text { insecurity-nervousness }\end{array}$ & $\begin{array}{l}0.13 \\
0.29\end{array}$ & $\begin{array}{l}0.78 \\
0.91\end{array}$ & $\begin{array}{l}0.09 \\
0.00\end{array}$ & $\begin{array}{l}\text { injustice-insecurity } \\
\text { insecurity-neryousness }\end{array}$ & $\begin{array}{l}0.18 \\
0.37\end{array}$ & $\begin{array}{l}0.09 \\
0.90\end{array}$ & $\begin{array}{l}0.06 \\
0.00\end{array}$ \\
\hline $\begin{array}{l}\text { lnsecurity-nervousness } \\
\text { injustice-nervousness }\end{array}$ & $\begin{array}{l}0.29 \\
0.43\end{array}$ & $\begin{array}{l}0.91 \\
1.08\end{array}$ & $\begin{array}{l}0.00 \\
0.00\end{array}$ & $\begin{array}{l}\text { Insecurity-nervousness } \\
\text { injustice-nervousness }\end{array}$ & $\begin{array}{l}0.37 \\
0.55\end{array}$ & $\begin{array}{l}0.90 \\
1.19\end{array}$ & $\begin{array}{l}0.00 \\
0.00\end{array}$ \\
\hline injustice-luck & -0.07 & 1.16 & 0.56 & injustice-luck & -0.02 & 0.94 & 0.83 \\
\hline competition-luck & 0.13 & 1.21 & 0.26 & competition-luck & 0.04 & 1.08 & 0.71 \\
\hline luck-demotivation & 0.23 & 1.07 & 0.28 & luck-demotivation & -0.09 & 1.22 & 0.68 \\
\hline obstacle-demotivation & 0.15 & 1.00 & 0.44 & obstacle-demotivation & 0.38 & 1.05 & 0.04 \\
\hline obstacle-conformity & -0.06 & 0.98 & 0.56 & obstacle-conformity & 0.08 & 1.04 & 0.44 \\
\hline imposition-competition & -0.13 & 1.32 & 0.31 & imposition-competition & -0.32 & 1.28 & 0.01 \\
\hline
\end{tabular}

\section{Source: coauthors' calculations}

\section{Students' opinion about their ideal image of the evaluation}

As for the ideal image of evaluation, i.e. what students see as desirable in the assessment in the two periods of inquiry, Justice seems to be the most valued one. In the first period of inquiry, 276 students chose this "value", which corresponds to $79.3 \%$ of total respondents. Of those, 181 students (52\%) have chosen it in the first place, that is, the most important item idealised in the evaluation. In the second period of inquiry, notwithstanding the value of justice which continues to be the most referenced one by this group of students, there was a decrease in their indication of the ideal image of evaluation. This item was chosen by 122 students, which corresponds to $56.2 \%$ of the sample of the second inquiry. However, and as the first option, 
only $34.6 \%$ of students have indicated it, which contrasts with the $52 \%$ of students from the first inquiry who have indicated it as their first option (see table 5).

The second most indicated item in the ideal image of the evaluation is the evaluation of "competencies" in the two periods of inquiry. In the first period of inquiry, $236(=67.8 \%)$ of the students have mentioned it. However, as a first option, only $18.1 \%$ of the students of the sample has chosen this item. Similarly, in the second period of inquiry, which was also the most chosen one, 124 students (=57.1\%) have replied. Of these, only $18.4 \%$ chose it first place (see table 5)

Table 5: Relative frequency of the answers in each of the image item that should be the evaluation by moments of inquiry and by order of choice/ranking

\begin{tabular}{|c|c|c|c|c|c|c|}
\hline \multirow[t]{2}{*}{ Evaluation image/Ranking } & \multicolumn{6}{|l|}{$\begin{array}{l}\text { Relative } \\
\text { frequency }\end{array}$} \\
\hline & $1^{o}$ & $2^{o}$ & $3^{o}$ & $4^{o}$ & $5^{0}$ & Omisso \\
\hline 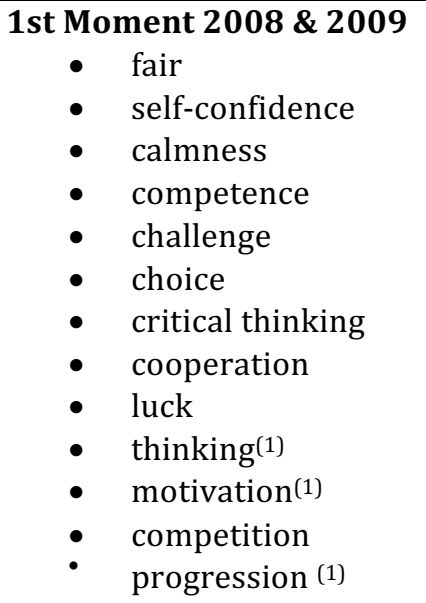 & $\begin{array}{c}52 \% \\
4.6 \% \\
3.2 \% \\
18.1 \% \\
6.9 \% \\
1.1 \% \\
2.3 \% \\
7.5 \% \\
0.9\end{array}$ & $\begin{array}{c}9.2 \% \\
10.3 \% \\
8.6 \% \\
28.7 \% \\
9.8 \% \\
6.0 \% \\
6.9 \% \\
12.1 \% \\
2.3\end{array}$ & $\begin{array}{c}9.5 \% \\
8.9 \% \\
9.2 \% \\
12.9 \% \\
9.5 \% \\
8.9 \% \\
15.8 \% \\
16.1 \% \\
0.6\end{array}$ & $\begin{array}{c}7.8 \% \\
10.3 \% \\
6.6 \% \\
6.9 \% \\
12.9 \% \\
6.0 \% \\
17.8 \% \\
17.0 \% \\
2.3\end{array}$ & $\begin{array}{c}0.9 \% \\
1.1 \% \\
1.4 \% \\
1.1 \% \\
1.7 \% \\
0.6 \% \\
0.6 \% \\
2.6 \% \\
0.9\end{array}$ & $\begin{array}{c}20.7 \% \\
64.7 \% \\
71 \% \\
32.2 \% \\
40.8 \% \\
77.3 \% \\
56.6 \% \\
44.8 \% \\
93.1 \% \\
100 \% \\
100 \% \\
97.1 \% \\
100 \%\end{array}$ \\
\hline $\begin{array}{ll}\text { 2nd Moment } 2016 \text { \& } 2017 \\
\text { - } & \text { fair } \\
\text { - } & \text { self-confidence } \\
\text { - } & \text { calmness } \\
\text { - } & \text { competence } \\
\text { - } & \text { challenge } \\
\text { - } & \text { choice } \\
\text { - } & \text { critical thinking } \\
\text { - } & \text { cooperation } \\
\text { - } & \text { luck } \\
\text { - } & \text { thinking(1) } \\
\text { - } & \text { motivation(1) } \\
\text { - } & \text { competition } \\
\text { - } & \text { progression }\end{array}$ & $\begin{array}{c}34.6 \% \\
4.6 \% \\
6.5 \% \\
18.4 \% \\
6.5 \% \\
1.8 \% \\
4.6 \% \\
3.2 \% \\
\\
5.1 \% \\
8.8 \% \\
1.8 \% \\
3.7 \%\end{array}$ & $\begin{array}{c}6.5 \% \\
4.1 \% \\
4.1 \% \\
24.4 \% \\
10.1 \% \\
4.6 \% \\
5.5 \% \\
6.5 \% \\
14.3 \% \\
1.4 \% \\
8.8 \%\end{array}$ & $\begin{array}{c}5.1 \% \\
4.1 \% \\
5.5 \% \\
6.5 \% \\
8.3 \% \\
1.8 \% \\
9.2 \% \\
7.4 \% \\
12.9 \% \\
17.5 \% \\
1.8 \% \\
15.2 \%\end{array}$ & $\begin{array}{c}8.8 \% \\
1.4 \% \\
5.1 \% \\
7.4 \% \\
7.8 \% \\
13.8 \% \\
7.4 \% \\
8.8 \% \\
54.8 \% \\
13.4 \% \\
1.8 \% \\
18 \%\end{array}$ & $\begin{array}{c}1.4 \% \\
0.5 \% \\
0 \% \\
0.5 \% \\
0.9 \% \\
37.9 \% \\
0.9 \% \\
0.0 \% \\
0.5 \% \\
13.8 \% \\
1.8 \% \\
0.9 \% \\
2.8 \%\end{array}$ & $\begin{array}{l}43.8 \% \\
85.3 \% \\
78.8 \% \\
57.1 \% \\
66.4 \% \\
86.6 \% \\
72.4 \% \\
72.8 \% \\
99.5 \% \\
99.5 \% \\
44.2 \% \\
99.2 \% \\
51.6 \%\end{array}$ \\
\hline
\end{tabular}

Source: coauthors' calculations

(1)_Variable of perception which has been introduced during the 2 nd moment of evaluation only.

\section{What does evaluation represent for students?}

We considered an open question on "How do students face evaluation". We classified and subdivided the answers into the following five types, whose absolute and relative frequencies are summarised in table 6:

1. The evaluation is associated with an image of challenge, game or competition,

2. The evaluation is linked to the fulfilment of objectives,

3. The evaluation is associated with negative aspects such as injustice and bad luck,

4. The evaluation is associated with aspects of reward and affection 
5. The evaluation is linked to other cases.

Table 6: Relative frequency of responses as to how is understood the evaluation by moments of inquiry (Free question: the evaluation is as ...)

\begin{tabular}{c|cc}
\hline \multicolumn{1}{c|}{ Area of Evaluation } & $\begin{array}{c}\text { Absolute } \\
\text { Frequency }\end{array}$ & $\begin{array}{c}\text { Relative } \\
\text { Frequency }\end{array}$ \\
\hline 1st moment of enquiry:2008 \& 2009 & 59 & $17 \%$ \\
- competition/game/challenge & 66 & $19 \%$ \\
- objetive/goal & 88 & $25.3 \%$ \\
- dificulty/injustice/chance & 56 & $16.1 \%$ \\
- importance/life/affection & 6 & $1.7 \%$ \\
- other cases & 73 & $21 \%$ \\
- not mentioned & & $26.7 \%$ \\
2nd moment of enquiry:2016 \& 2017 & 58 & $29.5 \%$ \\
- competition/game/challenge & 64 & $20.3 \%$ \\
- objetive/goal & 44 & $17.1 \%$ \\
- dificulty/injustice/chance & 37 & $0.5 \%$ \\
- importance/life/affection & 1 & $6 \%$ \\
- nother cases & 13 & \\
\hline
\end{tabular}

\section{Source: coauthors' calculations}

Although the students have a favourable opinion on the evaluation, there is still a negative feeling of about $25.3 \%$ of students in the first inquiry, which has fallen to $20.3 \%$ in the second period of inquiry. On the other hand, the evaluation accepted in a competitive environment and challenge obtained the opinion of $17 \%$ of the students in the first period of the inquiry, a percentage that rose to $26.7 \%$ in the second moment of enquiry. Considering the evaluation as a goal and an objective to reach, it deserved the opinion of $19 \%$ of students in the first period, becoming the highest opinion of the students in the second period of inquiry (29.5\%). Finally, evaluation ideas associated with emotional aspects as "life/love/passion", obtained an identical opinion in both periods, with $16.1 \%$ and $17.1 \%$, respectively.

\section{DISCUSSION}

Evaluation is probably the process that draws highly the attention of pupils and teachers in the teaching-learning process. Indeed, it can be an instrument which best enables us to further discussion on the progress of each student throughout his/her learning process. In what regards the learning success, which is also the success of the school, Rivkin et al. (2005) argue that both the teachers and the schools are important to enhance the school success. Therefore, the design of the evaluation in the teaching-learning process becomes the indicator that guides teachers and students. However, and according to Rivkin et al. (2005), the gains are systematically indexed to the performance of the teacher and the school characteristics. However, the evaluation under the emotional point of view embodies less positive aspects, such as nervousness, imposition and, sometimes, some sense of injustice.

The evaluation results encompass moments of frustration, nevertheless, almost all students incorporate it as a necessity of verification of skills and progression. Between the two periods of inquiry, which correspond to important moments in the process of implementation of the Bologna Declaration, it was observed that the sense of injustice has decreased, whilst we may underpin the increase the association of evaluation with the progression of learning and motivation. 
Evaluation appears to be the guiding compass of the learning outcomes, of the student's selfaffirming feeling before pre-designed objectives until the completion of their learning cycle. Probably as a result of less successful results, some students show a sense of deception about the evaluation procedure. Luck or chance still seem to linger in the mind of the students when they face the evaluation outcomes. If any initial nervousness before an evaluation instrument can be considered positive, leading the student to channel his/her efforts to the problem he/she is facing, excess stress/nervousness may certainly compromise the success of evaluation and will lead the emotionally negative thoughts about the role of evaluation in his/her teaching-learning process. Instead of a discussion about his/her progress, a negative perception of feelings of frustration and low self-esteem can determine his/her future attitudes regarding the teaching-learning process and drop out university. Indeed, the level of withdrawal in the courses is still rather high, representing about $20 \%$ of the students admitted to bachelor programmes, notwithstanding the Declaration of Bologna that claims to enshrine the inclusion and alternative solutions in the teaching-learning process.

Depending on the role of evaluation in the teaching and learning process, and in the light of the results obtained with our work, it seems to make sense to ask de following questions:

1. Does the teacher consider the evaluation as an instrument of the student's personal development? Is the evaluation student-centred or, on the contrary, is it teachercentred?

2. Is the evaluation considered by the students as an instrument of their own development process? Is it voicing the students or, on the contrary, is it silencing them?

3. Is the evaluation contemplating the holistic development of the student and the multiplicity of skills that will make him a citizen of excellence?

Evaluation is an indissociable part of the learning process. It is to be provided within the service of the students' development and help them identify possible weaknesses throughout their development. Therefore, the University should have training concerns for the enhancement of human, personal, social and community development of its students. For this reason, the University training should be integral and not just dedicate itself to specific skills and for the performance of specific professional tasks.

The University is a social institution in which students deepen their awareness about democratic values of socialisation and cooperation (Martínez, 2010); therefore, it is of paramount importance to humanise and render credible learning and evaluation processes. Nonetheless, this process should evolve into a spiral dynamics, which is why it is imperative to stimulate and gear a humanist and transparent reform. If the efforts of University reforms remain fragile and/or dependent of the political system or the like, new asset values of the citizen will not produce the desired effects and they will even produce negative external economies for the achievement of an overall social balance. Nevertheless, as the learning process has a physical face, that is the teacher, then he/she should invest in new teachinglearning methodologies and innovative evaluation methodologies, adapted to a society that is not kin on routines. As teachers are the co-creators of a new citizen, empathy, openness, justice and mentoring should be constant values to compromise all the learning process stakeholders, willing to seek after common objectives: justice, freedom, responsibility, solidarity and peace.

\section{CONCLUSION (FINAL REMARKS)}

The implementation of Bologna brought changes to models of teaching, but also new challenges both in terms of teaching and evaluation methodologies. "There is an ongoing important debate in the universities about the quantity and the quality of education in determining the results of education, measured either in terms of the achievement of the 
students and in terms of employment opportunities and the gains" (Iacus and Porrob, 2011, 139). When a system is remodeled, the results are not immediately visible. Sometimes it may even take years. When the learning outcomes are changed, the evaluation process should accommodate these changes. However, old evaluation experiences are maintained while students and teachers continue to focus on traditional education models. All stakeholders involved seem to resist to change. The evaluation experiences will interfere with students' opinion about the evaluation model and what they expect in terms of their academic performance success. If an examination is considered as an imposition and it is not accepted as an instrument to analyse progression, it may be a result of a teaching model based only on memorisation and the verification of acquired knowledge.

This study has highlighted different opinions of students in two periods of the implementation of the Bologna Declaration. It is interesting to outshine two final and conclusive aspects: the convergence of studies of the first cycle in accordance with the Bologna Declaration is not a uniform process, and there are significant differences in methodology and learning outcomes, regardless the fact that the Declaration unveils a convergence of teaching methodologies where one may underpin similarities in the professional needs and the teaching model.

With regard to 2nd cycle students, one would expect a more favourable perception of autonomy in the teaching-learning process. However, some indicators seem to contradict such a postulate. Evidence does signal the discrepancy that still persists between the teaching model and the students' expectations about the teaching-learning process. We also believe this may shed light upon a decontextualised model which does still override the contextualised model, where teaching and learning are built in a steady, evolutionary and cumulative manner.

\section{References}

Arriaga, C. (2009) Ensino de economia política no curso de Direito: uma experiência de adaptação curricular. In Flávia Vieira (org) Transformar a Pedagogia da Universidade - Narrativas da prática, De facto, Coleção Practicum, Porto, 137-151.

Chen Y. \& Hoshower L. (2003) Student Evaluation of Teaching Effectiveness: an assessment of student perception and motivation. Assessment \& Evaluation in Higher Education, 28 (1), 71-87.

Chen, T., Yang, S. \& Leo, C. (2017) The beginning of value co-creation: understanding dynamics, efforts and betterment, Journal of Service Theory and Practice, 27(6), 1145-1166.

Correia, I. \& Pereira, O. (2009) Spillovers de Conhecimento e Desenvolvimento Regional: O Papel Estratégico das Universidades. Eixo Atlântico - Revista da Eurorrexión Galicia-Norte de Portugal, 15, 73-92.

Dmochowski. J. E., Garofalo, D., Fisher, S, Greene, A. \& Gambogi, D. (2016) Integrating sustainability across the university curriculum, International Journal of Sustainability in Higher Education, 17(5), 652-670.

Hadji, C. (1994) A Avaliação, regras do jogo. Porto Editora, Porto.

Iacus S. \& Porrob G. (2011) Teachers' evaluations and students' achievement: a 'deviation from the reference' analysis. Education Economics, 19(2), 139-159.

Light G. \& Cox, R. (2001) Learning and Teaching in Higher Education, The Reflective Professional, London: Sage Publications.

Lizzio, A., Wilson K. \& Simons R. (2002) University Students' Perceptions of the Learning Environment and Academic Outcomes: implications for theory and practice. Studies in Higher Education, 27(1), 27-52.

Lyotard, J. F. (1979) La condition postmoderne, Paris: Ed. Minuit.

Martínez, M. (2010) Aprendizaje servicio y construcción de cidadania activa en la universidad: la dimension social y cívica delos aprendizajes académicos. In Martínez, M. (ed) (2010). Aprendizaje Servicio y responsabilidad social de las Universidades. Barcelona, Editorial Octaedro / ICE-UB, 11-26.

Nygaarda, C. \& Belluigib D. (2011) A proposed methodology for contextualised evaluation in higher education. Assessment \& Evaluation in Higher Education. 36(6), 657-671. 
Pereira, O. \& Coutinho, M. (2009) Knowledge Society and the Challenges to University Teaching: Application to Portugal - Estudios Económicos de Desarrollo Internacional, 9(2), 109-126.

Pereira, O. \& Costa, C. A. (2017a) The importance of soft skills in the university academic curriculum: The perceptions of the students in the new society of knowledge. International Journal of Business and Social Research, $7(3), 25-34$.

Pereira O. \& Costa C.A. (2017b) The University: An Institution of Co-creation and Social Transformation. Eastern European Business and Economics Journal 3(3), 245-269.

Rivkin S., Hanushek, E. \& Kain, J. (2005) Teachers Schools and Academic Achievement, Econometrica, 73(2), 417458.

Struyven, K., Dochy F. \& Janssens S.(2005) Students' perceptions about evaluation and assessment in higher education: a review. Assessment \& Evaluation in Higher Education, 30(4), 325-341.

Tavares, J.; Brzezinski, I.; Pereira, A.; Cabral, A.; Fernandes, A.; Silva, H.; Bessa, J. \& Carvalho, R. (2004) Docência e Aprendizagem no Ensino Superior", Investigar em Educação, 3, 15-55.

Vieira, F.; Silva, J. L.; Melo, M. C.; Moreira, M. A.; Oliveira, L. R.; Gomes, C; Albuquerque, P. B. \& Sousa, M. (2004), Transformar a pedagogia na universidade: experiências de investigação do ensino e da aprendizagem, Relatório de Investigação. Braga: Universidade do Minho, Research Centre for Education - Centro de Investigação em Educação. 